\title{
Mercado Internacional de Commodities Uma Análise da Participação do Brasil no Mercado Mundial de Soja entre 2008 e 2019
}

http://dx.doi.org/10.21527/2237-6453.2020.51.76-92

Recebido em: $17 / 4 / 2019$

Aceito em: 4/12/2019

\section{Patrícia Campeão, ${ }^{1}$ Arthur Caldeira Sanches, ${ }^{2}$ Wilson Ravelli Elizeu Maciel $^{3}$}

\begin{abstract}
RESUMO
A soja apresenta-se como uma das principais commodities comercializadas atualmente. Buscando uma análise sobre a concentração dos mercados mundiais de soja referente aos principais exportadores e uma visualização de como o Brasil aparece em tal cenário, o estudo em questão baseou-se em dados secundários para calcular a concentração de mercado $\mathrm{CR}(\mathrm{k})$ e o Índice Hirschman-Herfindahl. Observou-se uma forte concentração de participação de mercado no comércio mundial de soja, na qual os dois principais produtores do grão são responsáveis por, em média, $80 \%$ de todas as exportações mundiais no período estudado. Verificou-se que, embora o Brasil se classifique como o segundo maior produtor do grão, durante o período analisado, a partir de 2012 principalmente, o país assumiu a primeira colocação como principal exportador de soja do mundo, representando mais de $50 \%$ do total comercializado.
\end{abstract}

Palavras-chave: Mercado de commodities. Exportações de soja. Concentração de mercado.

\section{INTERNATIONAL COMMODITIES MARKET: AN ANALYSIS OF BRAZIL'S PARTICIPATION IN THE GLOBAL SOYBEAN MARKET BETWEEN 2008 AND 2019}

\begin{abstract}
Soybeans are one of the main commodities marketed today. Looking for an analysis of the concentration of the world soybean markets, referring to the main exporters and a visualization of how Brazil presents itself in such a scenario, the study in question used secondary data to calculate the market concentration CR (k) and the Hirschman-Herfindahl Index. There was a strong concentration of market share in world soybean trade, where the two main producers of soybeans are responsible for an average of $80 \%$ of all world exports in the period studied. Although Brazil ranks as the second largest producer of grain, during the period analyzed, from 2012, mainly, the country assumed the first position as the main exporter of soybeans in the world, representing more than $50 \%$ of the total marketed.
\end{abstract}

Keywords: Commodity market. Exports of soybeans. Market concentration.

\footnotetext{
${ }^{1}$ Doutora em Engenharia de Produção pela Universidade Federal de São Carlos (UFSCar). Professora da Universidade Federal de Mato Grosso do Sul (UFMS). patricia.campeao@ufms.br

${ }^{2}$ Doutor em Administração pela Universidade Federal de Mato Grosso do Sul (UFMS). Professor da Universidade Federal de Mato Grosso do Sul (UFMS). sanches.ac91@gmail.com

${ }^{3}$ Doutor em Administração pela Universidade Federal de Mato Grosso do Sul (UFMS). Professor da Universidade Federal de Mato Grosso do Sul (UFMS). wilson_ravelli@hotmail.com
} 
Oleaginosa típica de países temperados, a soja foi difundida em países tropicais e tornou-se uma das culturas mais bem estabelecidas no território brasileiro (MACEDO; NOGUEIRA, 2005). Sendo esta uma commodity, sua diferenciação ou competitividade se dará, fundamentalmente, em razão de seu preço. Neste, o Brasil é um dos destaques por apresentar vantagem comparativa oriunda da sua disponibilidade de recursos naturais e mão de obra (NEGRI, 2005).

A soja apresenta-se como uma das commodities mais relevantes no mercado internacional, e sua importância cresce à medida que esta é utilizada na composição de uma grande gama de produtos (FEDERIZZI, 2005), entre estes os alimentos de aves e suínos, fazendo com que a demanda pela soja aumente conforme o consumo da carne destes avança (AMARAL, 2009).

O consumo de soja e seus derivados vem crescendo em escala global. Primeiramente concentrado em países desenvolvidos, agora abrange novas regiões impulsionado pelo crescimento da renda dos consumidores e mudanças em seus hábitos de consumo. Em consequência, houve uma dispersão geográfica em termos de demanda e de concentração da produção em poucos países, além do aumento dos fluxos deste comércio (ZEMOLIN, 2013).

No território brasileiro a produção de soja iniciou-se nos anos 30 com a finalidade de suprir uma demanda existente da alimentação na suinocultura, passando a fazer parte das grandes exportações brasileiras apenas a partir do fim da Segunda Guerra Mundial, período em que o grão passou a ser utilizado na fabricação de óleos e rações comestiveis. A partir de 1963 seus subprodutos também passaram a ser comercializados (BATISTA FILHO, 1994).

Rocha e Mendonça (2004) discorre que, a partir da década de 50 até meados dos anos 70 do século 20, a soja passou a ganhar grande destaque dentre as exportações, contudo teve um momento de queda em 1980, com a baixa do preço do produto no mercado internacional em razão dos grandes estoques de grãos que haviam se formado na época.

Apesar das condições pouco favoráveis à exportação, em decorrência de um aquecimento do mercado interno sobre o produto, da redução da demanda externa por produtos brasileiros e da valorização da taxa de câmbio real, as exportações do complexo soja chegaram a representar $\mathrm{R} \$ 3,5$ bilhões nas exportações nacionais nos anos 90 (ROCHA; MENDONÇA, 2004). No início da década de 90 e nos anos 2000, a soja e seus derivados representaram a principal fonte de divisas do Brasil, com 30\% das exportações agrícolas e $10 \%$ das exportações totais do país (SAMPAIO; SAMPAIO; BERTRAND, 2012).

Neste sentido, a presente pesquisa busca investigar a participação do Brasil no comércio mundial da soja nos últimos dez anos, em especial sua participação nas exportações mundiais à luz da análise de concentração de mercado $C R(k)$ e Índice Hirschman-Herfindahl. De forma mais específica, visa-se a esboçar o grau de concentração dos mercados exportadores e comparar o crescimento das exportações de soja ante o total arrecadado com exportações no período de 2008 a 2019. 


\section{FUNDAMENTAÇÃO TEÓRICA}

\section{Commodities e a soja no mercado mundial}

Segundo Gasques et al. (1998), as commodities têm um grande espaço nas comercializações dentro do agribusiness internacional; isto em virtude do desafio de atender a uma significativa demanda por alimentos básicos para numerosos consumidores, além do fato de que a demanda pelo grão tem aumentado na medida em que a população mundial cresce e se urbaniza (GASQUES et al., 1998; COSTA et al., 2014).

De acordo com Zemolin (2013), principalmente no caso das commodities, há uma aproximação de um mercado perfeitamente competitivo, havendo, neste, nenhuma ou pouca diferenciação entre produtos, tornando pontos como a redução de custos e o aumento da produtividade, possíveis ações que resultam no aumento da competitividade; ações estas, segundo Ferraz, Kupfer e Haguenauer (1995), que perfazem principalmente a expansão de escalas de produção e padronização de processos.

Para Zemolin (2013), porém, mesmo no segmento de commodities, a estratégia de competitividade não necessita ser focada apenas em termos de concorrência no âmbito preços/custos ou na eficiência dos fatores de produção. Esta pode ser concebida, também, na forma de atribuição de valor adicionado aos produtos, como o atendimento às especificações particulares, prestação de serviços suplementares e investimento em áreas, como a ambiental, etc. por exemplo a soja, quando se investe em programas de pesquisa relacionados ao grau de gordura e óleos com propriedades específicas (FERRAZ; KUPFER; HAGUENAUER, 1995).

Condições naturais, intermediações comerciais, intervenções governamentais e acordos internacionais, contudo, fazem com que a produção de algumas commodities se torne mais vantajosa em determinados países, sendo esta produção demandada por todo o mundo. Essas condições permitem que um pequeno número de países, ou até mesmo um só, tenha o domínio das exportações no mercado internacional, propiciando a este(s) o poder sobre o mercado (CORONEL; MACHADO; CARVALHO, 2009).

Neste âmbito, Zemolin (2013) destaca que o mercado de commodities é altamente concentrado, dominado por poucos. Exemplo destes segmentos concentrados são os mercados internacionais de grão, farelo e óleo de soja, nos quais Argentina, Brasil e Estados Unidos apresentam poder de mercado englobando por volta de $85 \%$ das exportações mundiais (CORONEL, 2008).

A Argentina tem se consolidado na liderança das exportações de farelo de soja em razão de os Estados Unidos terem aumentado o consumo interno do produto, enquanto o Brasil privilegia as exportações do grão; isto desde a criação da lei complementar no 87, de 13 de setembro de 1996, conhecida como Lei Kandir, a qual isentou as exportações de produtos in natura do ICMS (Imposto Sobre Circulação de Mercadoria) (CORONEL; MACHADO; CARVALHO, 2009).

Federizzi (2005) aponta a soja como uma das commodities mais importantes no mercado internacional, em virtude de um conjunto de fatores que se relacionam à plasticidade da planta, da qualidade e quantidade de produtos que podem ser provenientes desta e da substituição da utilização de gordura animal por óleos de origem vegetal, apresentados como alternativas mais saudáveis. 
O aumento na produção de soja, uma vez que seu consumo se volta para a utilização de proteínas vegetais, é impulsionado pelo crescimento da demanda da carne de aves e suínos; isto porque parte da alimentação destes é composta pelo farelo de soja (AMARAL, 2009).

Para Nassar e Antoniazzi (2011), é o mercado de farelo do grão que determina a expansão da produção de soja, uma vez que, além de este ser utilizado como fonte de proteína nas rações de animais, se trata da fonte proteica mais barata do mundo (LOVATELLI, 2009).

Em se tratando do modelo de mercado perfeito, no que refere à competitividade, alguns fatores são postos como essenciais: grande número de produtores, livre-entrada e saída das empresas, produto homogêneo, livre-circulação das informações, maximização dos lucros e mobilidade perfeita dos fatores. Embora o desenvolvimento dos mercados de commodities pudesse trazer benefícios para vendedores e compradores do produto, este é colocado, muitas vezes, como um dos de maior concentração no mundo, sendo desenvolvido por quatro empresas principais: ADM, Bunge, Louis Dreyfus e Cargill (AZEVEDO, 2018).

Quando se analisa o mercado de soja, propriamente dito, em razão da uniformidade do produto, as análises desenvolvidas se baseiam nas diferenças estratégicas existentes entre os países produtores, buscando divergências no que diz respeito à competitividade dos agentes econômicos no ambiente do agronegócio, como no caso dos estudos desenvolvidos por Lazzarini e Nunes (2000), em que os autores avaliam aspectos microeconômicos, como apresentado na Tabela 1.

Tabela 1 - Fatores competitivos dos produtores de soja

\begin{tabular}{|l|c|c|c|}
\hline \multicolumn{1}{|c|}{ Variável avaliada } & Argentina & \multicolumn{1}{c|}{ Brasil } & Estados Unidos \\
\hline Recursos Naturais & & & \\
\hline Solo/clima & 3,16 & 2,78 & 2,94 \\
\hline Disponibilidade de áreas cultiváveis & 1,94 & 3,77 & 1,82 \\
\hline Nível tecnológico & & & \\
\hline Produção rural & 2,89 & 2,76 & 3,59 \\
\hline Indústria processadora & 2,94 & 2,76 & 3,52 \\
\hline Mão de obra & & & \\
\hline Qualidade & 2,88 & 2,69 & 3,31 \\
\hline Custo & 2,78 & 3,13 & 2,12 \\
\hline Mercado interno & & & \\
\hline Tamanho & 1,83 & 3,39 & 3,77 \\
\hline Potencial de crescimento & 2,19 & 3,44 & 2,5 \\
\hline Fatores sistêmicos & & & \\
\hline Infraestrutura logística & 2,78 & 2,24 & 3,94 \\
\hline Restrições tributárias & 3,11 & 2,16 & 3,6 \\
\hline Restrições financeiras & 2,83 & 2,22 & 3,83 \\
\hline Coordenação/cooperação ao longo do SAG & 2,83 & 2,67 & 3,39 \\
\hline
\end{tabular}

Fonte: LAZZARINI; NUNES, 2000. 
O estudo foi desenvolvido com base nas variáveis de recursos naturais, mão de obra, nível tecnológico, mercado interno e fatores sistêmicos, utilizando como ponto de análise os três principais produtores de soja do mundo: Brasil, Estados Unidos e Argentina. Embora o Brasil não se coloque com altas taxas nos fatores de competitividade listados, como custo da mão de obra, qualidade da mesma e infraestrutura logística, no que se refere ao tamanho, disponibilidade de áreas cultivadas e potencial de crescimento, $\mathrm{o}$ país se coloca como forte agente do mercado.

Tais estudos mostram que não apenas a soja se configura como importante mercadoria de comércio mundial, mas ainda se destaca como um dos principais produtos cultivados e exportados pelo Brasil, caracterizando o país como um dos principais fornecedores do mundo, o que ressalta a importância de trabalhos como este que visam a analisar o posicionamento nacional ante as exportações mundiais durante os anos, auxiliando na definição do comportamento do mercado de commodities.

\section{PROCEDIMENTOS METODOLÓGICOS}

A fim de analisar a participação do Brasil nas exportações mundiais de soja, foi conduzido um estudo quantitativo-descritivo (MALHOTRA, 2001) tendo como base dados secundários (MALHOTRA, 2001). Mediante relatórios sobre a produção e exportação de soja do Instituto Brasileiro de Geografia e Estatística (IBGE), da Companhia Nacional de Abastecimento (Conab), do Food and Agriculture Organization (FAO) e do United States Department of Agriculture (USDA), foram compostas as bases de informações utilizadas a fim de responder a questão de estudo.

Buscou-se realizar uma descrição do fenômeno (MARCONI; LAKATOS, 2002) por meio deste estudo, realizado em determinado período de tempo (2008 a 2019), de maneira a descrever as alterações nos índices de concentração e a participação do Brasil no mercado exportador de soja. Os dados obtidos foram agrupados para permitir as análises pretendidas e os cálculos de concentração de mercado CRk e índice Hirschman- Herfindahl, assim como as comparações sobre o crescimento da participação das exportações da commodity estudada perante o total gerado pelas exportações nacionais.

As medidas econômicas de concentração possuem como objetivo analisar a forma como os agentes impõem-se em um determinado mercado, ponderando tais participações por intermédio de critérios diferenciados (RESENDE; BOFF, 2002).

Segundo Resende (1994), tais medidas de concentração podem ser apresentadas em dois grupos distintos: sumário (utiliza como uma variável preestabelecida os dados de todas as empresas de uma determinada indústria ou setor, comparando tais dados com o total), ou parcial (usa os dados de um grupo específico das maiores empresas do ramo e compara com os resultados totais).

As parcelas de mercado são calculadas para cada agente, sendo o cálculo realizado seguindo a fórmula (GUJARATI, 2000):

$$
S_{i}=\frac{q_{i}}{\sum_{j=1}^{n} q_{j}}
$$


onde $\left(S_{i}\right)$ representa a parcela de mercado da empresa $i, q_{i}$ refere-se ao faturamento bruto da empresa em um ano e $\sum_{j=1}^{n}$ contabiliza o faturamento bruto dos " $\mathrm{n}$ " agentes do mercado.

A concentração de mercado (CRk) é definida para um número $k$ de agentes no mercado, sendo obtida a partir da seguinte fórmula:

$$
C R K=\sum_{i=1}^{k} S_{i}
$$

onde $k$ representa o número de agentes considerados para o cálculo. Os valores $C R k$ são expressos em porcentagens ou em decimais, indicando a parcela de mercado atribuída às maiores empresas do setor.

O índice HH nos dá outras informações sobre o grau de concentração de forma mais detalhada. Seu cálculo é realizado pela soma dos quadrados da parcela de mercado de cada um dos agentes, como:

$$
H H=\sum_{i=1}^{k} S_{i}^{2}
$$

Os valores são expressos na forma decimal ou em percentual. Ao se utilizar valores decimais de $\mathrm{HH}$, estes variam entre zero e um. Valores próximos a zero indicam um maior número de agentes no mercado com uma distribuição mais semelhante entre suas parcelas de mercado; já valores de $\mathrm{HH}$ próximos a um sugerem um número menor de agentes no setor e uma desigualdade significativa entre estes (MARTIN, 1993).

Segundo Schmidt e Lima (2002), o Índice Hirschamn-Herfindahl segue algumas regras utilizadas para a aprovação de um Ato de Concentração, sendo elas:

a. IHH menor que 0,10 representa mercado que não era concentrado antes e continuou desconcentrado;

b. IHH entre 0,10 e 0,18 representa mercados em que há um aumento do poder coordenado;

c. Mercados com IHH acima de 0,18 são considerados concentrados.

d.

\section{RESULTADOS E DISCUSSÃO}

Partindo do objetivo proposto neste trabalho, de analisar a participação do Brasil nas exportações mundiais de soja no que se refere à concentração deste mercado, foram levantados dados em bases secundárias como sites da Conab, Usda, Fiesp e MDIC para a identificação do comportamento da venda desta commodity nos últimos anos.

Assim, a Tabela 2 apresenta como encontra-se distribuída a produção de soja em algumas regiões, partindo do macroambiente (produção mundial) até ambientes mais localizados, como os principais Estados produtores brasileiros. 
Tabela 2 - Produção de soja em 2019

\begin{tabular}{|c|c|c|c|c|c|c|}
\hline & $\begin{array}{c}\text { Soja } \\
\text { Mundo }\end{array}$ & $\begin{array}{c}\text { Soja América } \\
\text { do Sul }\end{array}$ & $\begin{array}{c}\text { Soja } \\
\text { EUA }\end{array}$ & $\begin{array}{c}\text { Soja } \\
\text { Brasil }\end{array}$ & $\begin{array}{c}\text { Mato } \\
\text { Grosso }\end{array}$ & $\begin{array}{c}\text { Rio Grande } \\
\text { do Sul }\end{array}$ \\
\hline $\begin{array}{c}\text { Produção (milhões } \\
\text { de toneladas) }\end{array}$ & 362,9 & 182,117 & 123,7 & 114,843 & 32,454 & 19,187 \\
\hline $\begin{array}{c}\text { Área Plantada } \\
\text { (milhões de hectares) }\end{array}$ & 125,691 & 59,487 & 35,657 & 35,874 & 9,699 & 5,778 \\
\hline
\end{tabular}

Fonte: EMBRAPA (2019).

Como é possível verificar na Tabela 2, com base na quantidade total de soja produzida no mundo no ano de 2019 , nota-se uma concentração significativa da produção total na América do Sul e nos Estados Unidos, de modo que ambos somam $84,27 \%$ de todo o grão produzido. Da mesma forma, é possível verificar que os dados apontam para uma forte influência do Brasil no resultado final da produção da América do Sul, ao representar, sozinho, 63\% de toda soja produzida na Região Sul do Continente Americano. Isso implica identificação de dois países que se classificam como fortes produtores da commodity - Brasil e Estados Unidos -, com uma participação conjunta de $65 \%$ do total de soja produzida no ano de 2019.

Dentro do território nacional, por sua vez, foram listados os dois Estados que mais produziram o produto (Mato Grosso e Rio Grande do Sul) em 2019. A comparação entre ambos indica também uma concentração na produção de soja dentro do próprio território brasileiro, de maneira que um Estado se coloca muito à frente dos demais no que diz respeito à produção de soja. Analiticamente, o Estado do Mato Grosso produz quase duas vezes mais soja do que o segundo colocado (Rio Grande do Sul).

Sobre o desenvolvimento das exportações nacionais de soja, a Tabela 3 apresenta o volume de grãos exportados pelo país (desde 2005) e o valor em milhões de dólares arrecadados com essa venda.

Tabela 3 - Valores monetários e volumes de exportações brasileiras de soja

\begin{tabular}{|c|c|c|}
\hline Ano & Exportação de Soja (US\$ bilhões) & Exportação de Soja (mil toneladas) \\
\hline $\mathbf{2 0 0 5}$ & 5,34 & 22.435 \\
\hline $\mathbf{2 0 0 6}$ & 5,66 & 24.957 \\
\hline $\mathbf{2 0 0 7}$ & 6,7 & 23.733 \\
\hline $\mathbf{2 0 0 8}$ & 10,95 & 24.499 \\
\hline $\mathbf{2 0 0 9}$ & 11,42 & 28.562 \\
\hline $\mathbf{2 0 1 0}$ & 11,04 & 29.073 \\
\hline $\mathbf{2 0 1 1}$ & 16,32 & 32.985 \\
\hline $\mathbf{2 0 1 2}$ & 17,24 & 32.468 \\
\hline $\mathbf{2 0 1 3}$ & 22,81 & 45.692 \\
\hline $\mathbf{2 0 1 4}$ & 23,28 & 54.324 \\
\hline $\mathbf{2 0 1 5}$ & 20,98 & 51.581 \\
\hline $\mathbf{2 0 1 6}$ & 19,33 & 68.154 \\
\hline $\mathbf{2 0 1 7}$ & 25,72 & 83.257 \\
\hline $\mathbf{2 0 1 8}$ & 33,19 & 70.000 \\
\hline
\end{tabular}

Fonte: MDIC (2019); CONAB (2019). 
Os valores apresentados sobre quantidade exportada, em milhares de toneladas, indicam que, embora a exportação de soja possa ter sofrido algumas variações negativas no período de 13 anos, como no caso dos volumes vendidos entre os anos de 2006 e 2008, no geral as vendas internacionais do produto cresceram significativamente no período analisado, passando de pouco mais de 22 milhões de toneladas para $83 \mathrm{mi}$ Ihões de toneladas vendidas no ano de 2017 . Isso reflete um aumento de $371 \%$ nas exportações em menos de 15 anos. O mesmo pode ser observado nos valores monetários recebidos pela exportação brasileira, que subiram, expressivamente, entre 2005 e 2018. Embora a quantidade maior de grãos vendida esteja diretamente vinculada ao aumento da renda gerada com a atividade, também se deve considerar o aumento gradativo do preço do bem.

A Tabela 4 mostra como se comportou a produção e exportação total de soja, no mundo, entre as safras de 2008/09 e 2019/20.

Tabela 4 - Volume de Produção e exportação mundial de soja - 2008/09 - 2019/20

\begin{tabular}{|c|c|c|}
\hline Safra & Produção (milhões de toneladas) & Exportações (milhões de toneladas) \\
\hline $\mathbf{2 0 0 8 / 0 9}$ & 211,64 & - \\
\hline $\mathbf{2 0 0 9 / 1 0}$ & 261,09 & - \\
\hline $\mathbf{2 0 1 0 / 1 1}$ & 264,2 & 92,4 \\
\hline $\mathbf{2 0 1 1 / 1 2}$ & 239,6 & 90,4 \\
\hline $\mathbf{2 0 1 2 / 1 3}$ & 268 & 99,9 \\
\hline $\mathbf{2 0 1 3 / 1 4}$ & $\mathbf{2 8 5 , 3}$ & 112,8 \\
\hline $\mathbf{2 0 1 4} / \mathbf{1 5}$ & 319 & 126 \\
\hline $\mathbf{2 0 1 5 / 1 6}$ & 313,3 & 132 \\
\hline $\mathbf{2 0 1 6 / 1 7}$ & 351,3 & 147,7 \\
\hline $\mathbf{2 0 1 7 / 1 8}$ & 348,9 & 152,4 \\
\hline $\mathbf{2 0 1 8 / 1 9}$ & 339,5 & 153,2 \\
\hline $\mathbf{2 0 1 9} / \mathbf{2 0}$ & 362,9 & 148,3 \\
\hline
\end{tabular}

Fonte: FIESP (2019).

Embora a produção mundial tenha crescido de maneira mais singela do que aquela apresentada no Brasil, ainda é possível observar uma evolução de mais de $50 \%$ dentre as safras de 2008 e as safras de 2019. No mesmo ritmo, a quantidade de exportações passou de 92 milhões de toneladas em 2010 para 148 milhões de toneladas em 2019. Os dados sobre as exportações mundiais dos primeiros anos (2008 e 2009), analisados na Tabela 4, não puderam ser identificados em razão da falta de dados decorrente da substituição das informações por atualizações nas bases de dados buscadas. Isso mostra que não apenas a produção de soja do Brasil, mas do mundo, vem se desenvolvendo gradativamente com cada vez mais agentes econômicos produzindo e maior demanda internacional para o uso da soja, caracterizando a análise do mercado como algo importante e atual.

Neste sentido, como apontado por Coronel, Machado e Carvalho (2009), condições naturais, intermediações comerciais, intervenções governamentais e acordos internacionais fazem com que a produção de algumas commodities se torne mais vantajosa em determinados países, permitindo que um pequeno número de países tenha o 
domínio das exportações e o poder sobre o mercado, como é o caso dos países listados na Tabela 5, em que o Brasil recebe destaque por possuir a seu favor fatores naturais, como a disponibilidade de áreas cultiváveis e potencial de crescimento.

A Tabela 5 apresenta a produção (em milhões de toneladas) dos principais produtores de soja no mundo. Em seguida, a Tabela 6 traz os valores percentuais dessa produção de soja para auxiliar na identificação da concentração de mercado da commodity.

Tabela 5 - Produção dos principais países produtores de soja em milhares de toneladas

\begin{tabular}{|c|c|c|c|c|c|c|c|c|c|c|c|c|}
\hline & $\mathbf{2 0 0 8}$ & $\mathbf{2 0 0 9}$ & $\mathbf{2 0 1 0}$ & $\mathbf{2 0 1 1}$ & $\mathbf{2 0 1 2}$ & $\mathbf{2 0 1 3}$ & $\mathbf{2 0 1 4}$ & $\mathbf{2 0 1 5}$ & $\mathbf{2 0 1 6}$ & $\mathbf{2 0 1 7}$ & $\mathbf{2 0 1 8}$ & $\mathbf{2 0 1 9}$ \\
& $\mathbf{2 0 0 9}$ & $\mathbf{2 0 1 0}$ & $\mathbf{2 0 1 1}$ & $\mathbf{2 0 1 2}$ & $\mathbf{2 0 1 3}$ & $\mathbf{2 0 1 4}$ & $\mathbf{2 0 1 5}$ & $\mathbf{2 0 1 6}$ & $\mathbf{2 0 1 7}$ & $\mathbf{2 0 1 8}$ & $\mathbf{2 0 1 9}$ & $\mathbf{2 0 2 0}$ \\
\hline Brasil & 57,8 & 69,0 & 75,5 & 66,5 & 81,0 & 86,7 & 97,2 & 96,5 & 114,6 & 122,0 & 117,0 & 123,0 \\
\hline EUA & 80,7 & 91,4 & 90,6 & 84,2 & 77,8 & 91,4 & 106,9 & 106,9 & 116,9 & 120,1 & 123,7 & 104,6 \\
\hline Argentina & 32,0 & 54,5 & 49,0 & 41,0 & 55,0 & 53,4 & 61,4 & 58,8 & 55,0 & 37,8 & 56,0 & 53,0 \\
\hline China & 15,5 & 14,9 & 15,1 & 13,5 & 12,6 & 12,0 & 12,2 & 12,4 & 13,6 & 15,2 & 15,9 & 17,0 \\
\hline Índia & 9,1 & 9,7 & 9,8 & 11,0 & 11,5 & 9,5 & 8,7 & 6,9 & 11,0 & 8,4 & 11,5 & 10,9 \\
\hline Paraguai & 3,7 & 7,4 & 8,3 & 4,0 & 8,1 & 8,2 & 8,2 & 9,2 & 10,3 & 10,3 & 9,0 & 10,2 \\
\hline Canadá & 3,3 & 3,5 & 4,3 & 4,2 & 4,3 & 5,4 & 6,0 & 6,5 & 6,6 & 7,7 & 7,3 & 6,2 \\
\hline Outros & 9,4 & 10,6 & 12,0 & 13,6 & 13,9 & 16,3 & 19,5 & 19,4 & 22,5 & 20,1 & 22,5 & 22,1 \\
\hline Total & 211,6 & 261,1 & 264,7 & 238,1 & 264,3 & 282,7 & 320,0 & 316,6 & 350,6 & 341,5 & 362,9 & 347,0 \\
\hline
\end{tabular}

Fonte: USDA 2019.

Tabela 6 - Participação da produção dos principais países produtores de soja (em \%)

\begin{tabular}{|c|c|c|c|c|c|c|c|c|c|c|c|c|}
\hline & $\mathbf{2 0 0 8}$ & $\mathbf{2 0 0 9}$ & $\mathbf{2 0 1 0}$ & $\mathbf{2 0 1 1}$ & $\mathbf{2 0 1 2}$ & $\mathbf{2 0 1 3}$ & $\mathbf{2 0 1 4}$ & $\mathbf{2 0 1 5}$ & $\mathbf{2 0 1 6}$ & $\mathbf{2 0 1 7}$ & $\mathbf{2 0 1 8}$ & $\mathbf{2 0 1 9}$ \\
& $\mathbf{2 0 0 9}$ & $\mathbf{2 0 1 0}$ & $\mathbf{2 0 1 1}$ & $\mathbf{2 0 1 2}$ & $\mathbf{2 0 1 3}$ & $\mathbf{2 0 1 4}$ & $\mathbf{2 0 1 5}$ & $\mathbf{2 0 1 6}$ & $\mathbf{2 0 1 7}$ & $\mathbf{2 0 1 8}$ & $\mathbf{2 0 1 9}$ & $\mathbf{2 0 2 0}$ \\
\hline Brasil & 27,3 & 26,4 & 28,5 & 27,9 & 30,7 & 30,7 & 30,4 & 30,5 & 32,7 & 35,7 & 32,2 & 35,4 \\
\hline EUA & 38,2 & 35,0 & 34,2 & 35,4 & $\mathbf{2 9 , 5}$ & 32,3 & 33,4 & 33,8 & 33,4 & 35,2 & 34,1 & 30,2 \\
\hline Argentina & 15,1 & 20,9 & 18,5 & 17,2 & 20,8 & 18,9 & 19,2 & 18,6 & 15,7 & 11,1 & 15,4 & 15,3 \\
\hline China & 7,3 & 5,7 & 5,7 & 5,7 & 4,8 & 4,2 & 3,8 & 3,9 & 3,9 & 4,5 & 4,4 & 4,9 \\
\hline Índia & 4,3 & 3,7 & 3,7 & 4,6 & 4,4 & 3,4 & 2,7 & 2,2 & 3,1 & 2,4 & 3,2 & 3,1 \\
\hline Paraguai & 1,7 & 2,8 & 3,1 & 1,7 & 3,1 & 2,9 & 2,6 & 2,9 & 3,0 & 3,0 & 2,5 & 2,9 \\
\hline Canadá & 1,6 & 1,3 & 1,6 & 1,8 & 1,6 & 1,9 & 1,9 & 2,0 & 1,9 & 2,3 & 2,0 & 1,8 \\
\hline Outros & 4,5 & 4,1 & 4,5 & 5,7 & 5,3 & 5,8 & 6,1 & 6,1 & 6,4 & 5,9 & 6,2 & 6,4 \\
\hline Total & 100 & 100 & 100 & 100 & 100 & 100 & 100 & 100 & 100 & 100 & 100 & 100 \\
\hline
\end{tabular}

Fonte: Elaborada pelos autores.

De acordo com os dados das primeiras duas linhas, respectivamente Brasil e Estados Unidos, nota-se que ambos os países revezam a primeira colocação como principal produtor de soja no mundo, sendo o Brasil classificado como o primeiro do ranking no ano de 2019 , retendo mais de $35 \%$ da produção total.

Segundo Pimenta (2017), na safra 2012/13 o Brasil passou a desenhar seu movimento para safras recordes, sendo beneficiado pelo fato de que não houveram problemas graves durante a evolução do desenvolvimento vegetativo. O resultado do país foi impactado pelo desempenho da Região Centro-Sul, que registrou um aumento de $15,1 \%$ na produção. É importante apontar também para o período $2015 / 16$, no qual ocorreu a elevação de preços na Bolsa de Chicago (CBOT). A falta de chuva e o replantio de algumas áreas acarretaram uma queda da produção geral do país, resultando um 
desempenho menor do que no período anterior. Já na safra 2016/17 houve um desempenho recorde, propiciada pelo clima adequado ao desenvolvimento das lavouras em todas as regiões produtoras do país.

Com relação à produção de soja na América do Sul, cabe considerar que os principais países produtores - Brasil e Argentina -, mesmo vizinhos, apresentam cenários distintos. No Brasil, como pode ser observado, a produção já ultrapassa 100 milhões de toneladas, alcançando o historicamente maior produtor mundial - os Estados Unidos. Já em relação à Argentina, o cenário promissor é freado por condições climáticas que inviabilizam uma considerável quantidade de lavouras e pelo imposto sobre a exportação de soja, chamada "retenciones", que propiciou crescimento mais expressivo da área cultivada de milho em detrimento da área destinada à produção de soja, o que pode explicar a queda na produção na safra 2017/18 (GU; PATTON, 2019).

Sobre os dados do desempenho da produção Argentina, é importante salientar que, conforme Pimenta (2017), a safra 2013/14 foi prejudicada em razão de umidade excessiva em determinadas localidades decorrentes de abundantes chuvas durante parte dos estágios vegetativos e reprodutivos do cultivo, o que propiciou o desenvolvimento de fungos e a propagação de pragas, provocando a morte súbita de inúmeros lotes do commodity. A perda estimada foi de 860.000 hectares. Da mesma forma, o baixo crescimento durante 2015/16 e a perda de área expressiva em 2016/17, podem ser explicados pelas condições climáticas durante o período do desenvolvimento do cultivo, no qual houve inundações e alagamentos nas principais áreas produtivas do país, resultando da perda de área de plantio de 1,2 milhões de hectares (PIMENTA, 2017).

Com relação a países fora da América do Sul, a presença da China merece algumas considerações, posto que este país vem investindo na produção de soja, fato este que pode ser atribuído à necessidade chinesa de buscar a segurança alimentar de 1,3 biIhões de pessoas, fazendo com que o país invista na produção interna impulsionada por um plano de revitalização da produção nacional da oleaginosa, além do investimento nas estruturas de importações. Nesse cenário, a China vem realizando investimentos no Brasil desde o ano de 2009, a fim de estabelecer parceria para suprir suas necessidades (GU; PATTON, 2019).

Além disso, existe ainda o fato de que a China, que usa soja para produzir ração para suas criações, tem realizado esforço para reduzir sua dependência das importações do grão dos EUA, em razão das crescentes tensões comerciais entre os dois países (GU; PATTON, 2019).

Em relação às exportações, a Tabela 7 apresenta o volume total de grãos e a Tabela 8 o percentual respectivo de cada país no total de soja exportada naquele ano.

Tabela 7 - Volume de exportações dos principais países exportadores de soja em milhares de toneladas

\begin{tabular}{|c|c|c|c|c|c|c|c|c|c|c|c|c|}
\hline & $\mathbf{2 0 0 8}$ & $\mathbf{2 0 0 9}$ & $\mathbf{2 0 1 0}$ & $\mathbf{2 0 1 1}$ & $\mathbf{2 0 1 2}$ & $\mathbf{2 0 1 3}$ & $\mathbf{2 0 1 4}$ & $\mathbf{2 0 1 5}$ & $\mathbf{2 0 1 6}$ & $\mathbf{2 0 1 7}$ & $\mathbf{2 0 1 8}$ & $\mathbf{2 0 1 9}$ \\
& $\mathbf{2 0 0 9}$ & $\mathbf{2 0 1 0}$ & $\mathbf{2 0 1 1}$ & $\mathbf{2 0 1 2}$ & $\mathbf{2 0 1 3}$ & $\mathbf{2 0 1 4}$ & $\mathbf{2 0 1 5}$ & $\mathbf{2 0 1 6}$ & $\mathbf{2 0 1 7}$ & $\mathbf{2 0 1 8}$ & $\mathbf{2 0 1 9}$ & $\mathbf{2 0 2 0}$ \\
\hline Brasil & 30,0 & $\mathbf{2 8 , 6}$ & $\mathbf{2 9 , 9}$ & $\mathbf{3 6 , 3}$ & $\mathbf{3 7 , 4}$ & $\mathbf{4 6 , 8}$ & 50,6 & 54,4 & 63,1 & 76,2 & 76,9 & 76,0 \\
\hline EUA & 34,8 & 40,8 & $\mathbf{4 0 , 8}$ & 37,0 & 34,4 & 44,6 & 50,1 & 52,9 & 59,0 & 58,1 & 46,3 & 51,0 \\
\hline Argentina & 5,6 & 13,1 & 9,2 & 7,6 & 12,0 & 7,8 & 10,6 & 9,9 & 7,0 & 2,1 & 7,8 & 8,0 \\
\hline Paraguai & 2,3 & 5,6 & 6,7 & 3,1 & 5,4 & 4,8 & 4,6 & 5,4 & 6,1 & 6,0 & 5,6 & 6,2 \\
\hline
\end{tabular}




\begin{tabular}{|c|c|c|c|c|c|c|c|c|c|c|c|c|}
\hline Canadá & 2,0 & 2,2 & 2,9 & 2,9 & 2,9 & 3,5 & 3,8 & 4,2 & 4,6 & 4,9 & 5,0 & 4,2 \\
\hline Outros & 2,2 & 2,5 & 3,0 & 3,5 & 4,0 & 5,1 & 6,5 & 5,8 & 7,7 & 5,8 & 6,8 & 5,8 \\
\hline Total & 76,9 & 92,8 & 92,6 & 90,4 & 96,2 & 112,7 & 126,2 & 132,6 & 147,5 & 153,1 & 148,3 & 151,3 \\
\hline
\end{tabular}

Fonte: Elaborada pelos autores.

Tabela 8 - Participação da exportação dos principais países exportadores de soja (em \%)

\begin{tabular}{|c|c|c|c|c|c|c|c|c|c|c|c|c|}
\hline & $\mathbf{2 0 0 8}$ & $\mathbf{2 0 0 9}$ & $\mathbf{2 0 1 0}$ & $\mathbf{2 0 1 1}$ & $\mathbf{2 0 1 2}$ & $\mathbf{2 0 1 3}$ & $\mathbf{2 0 1 4}$ & $\mathbf{2 0 1 5}$ & $\mathbf{2 0 1 6}$ & $\mathbf{2 0 1 7}$ & $\mathbf{2 0 1 8}$ & $\mathbf{2 0 1 9}$ \\
& $\mathbf{2 0 0 9}$ & $\mathbf{2 0 1 0}$ & $\mathbf{2 0 1 1}$ & $\mathbf{2 0 1 2}$ & $\mathbf{2 0 1 3}$ & $\mathbf{2 0 1 4}$ & $\mathbf{2 0 1 5}$ & $\mathbf{2 0 1 6}$ & $\mathbf{2 0 1 7}$ & $\mathbf{2 0 1 8}$ & $\mathbf{2 0 1 9}$ & $\mathbf{2 0 2 0}$ \\
\hline Brasil & 39,0 & 30,8 & 32,3 & $\mathbf{4 0 , 2}$ & $\mathbf{3 8 , 9}$ & $\mathbf{4 1 , 5}$ & $\mathbf{4 0 , 1}$ & 41,0 & $\mathbf{4 2 , 8}$ & $\mathbf{4 9 , 8}$ & 51,8 & 50,2 \\
\hline EUA & 45,3 & 43,9 & 44,1 & 40,9 & 35,8 & 39,6 & 39,7 & 39,9 & 40,0 & 37,9 & 31,2 & 33,7 \\
\hline Argentina & 7,3 & 14,1 & 9,9 & 8,4 & 12,5 & 7,0 & 8,4 & 7,5 & 4,8 & 1,4 & 5,2 & 5,3 \\
\hline Paraguai & 3,0 & 6,1 & 7,2 & 3,4 & 5,6 & 4,3 & 3,6 & 4,1 & 4,2 & 3,9 & 3,8 & 4,1 \\
\hline Canadá & 2,6 & 2,4 & 3,2 & 3,2 & 3,0 & 3,1 & 3,0 & 3,2 & 3,1 & 3,2 & 3,4 & 2,8 \\
\hline Outros & 2,9 & 2,7 & 3,3 & 3,9 & 4,2 & 4,6 & 5,2 & 4,4 & 5,2 & 3,8 & 4,6 & 3,9 \\
\hline Total & 100 & 100 & 100 & 100 & 100 & 100 & 100 & 100 & 100 & 100 & 100 & 100 \\
\hline
\end{tabular}

Fonte: Elaborada pelos autores.

No que se refere às exportações de soja, embora o Brasil tenha se colocado, poucas vezes durante o período analisado, como principal produtor de soja do mundo, este se destaca nas vendas do grão para as demais regiões do planeta, classificando-se como o principal exportador na maioria dos anos avaliados, chegando até mesmo a representar, sozinho, mais de $50 \%$ das exportações realizadas no ano, como no caso dos dados referentes a 2019/20. Juntamente com a capacidade de venda dos Estados Unidos, os dois países concentram mais de $80 \%$ de todas as exportações de soja realizadas no globo.

Quanto ao desempenho da Argentina, verifica-se uma diminuição nas exportações ao longo do período, principalmente em 2017/18, ocasionada pelas chamadas "retenciones", conforme abordado anteriormente, que têm prejudicado o aumento de área do plantio de soja no país, o que implica na produção do commodity e, consequentemente, na sua exportação (PIMENTA, 2017).

A variação na participação no mercado de cada um dos principais produtores de soja pode ser observada, de maneira mais clara, no Gráfico 1.

Gráfico 1 - Market share - Exportações de soja

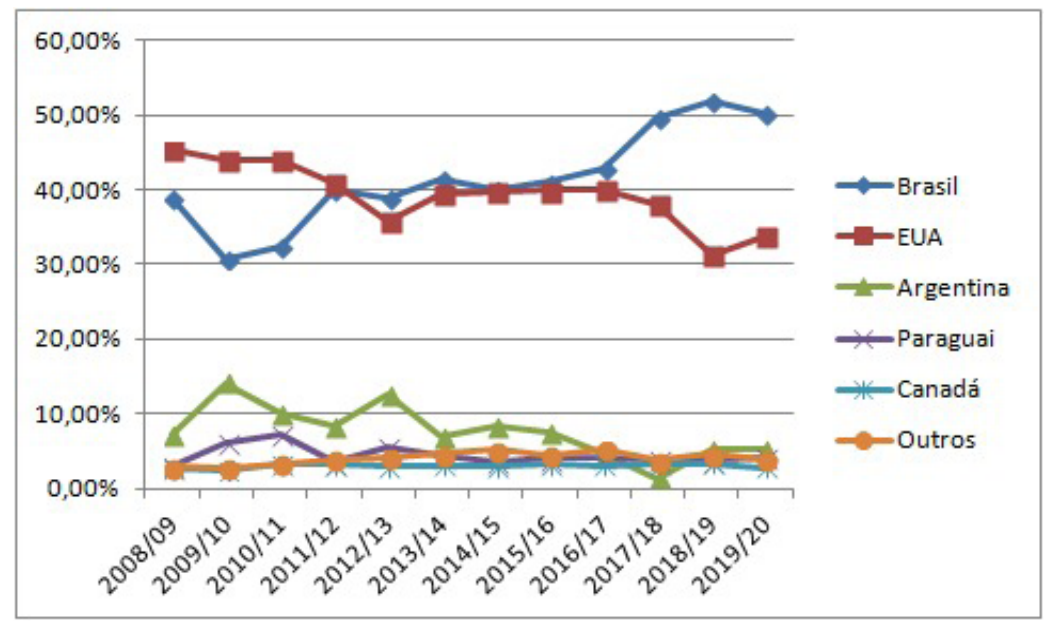

Fonte: Elaborado pelos autores. 
As linhas presentes no Gráfico 1 representam o desenvolvimento do market share de cada um dos cinco principais produtores de soja no mundo, ou seja, a fatia de mercado que cada um desses países atende mediante as exportações realizadas do insumo. Nota-se que há dois cenários muito distintos ilustrados: o dos maiores exportadores (Brasil e EUA) e dos outros três países que fazem parte do gráfico. Embora esses últimos sejam classificados como terceiro, quarto e quinto maiores exportadores do grão, os mesmos encontram-se em dimensões muito distintas dos primeiros colocados, os quais concentram, em média, $80 \%$ dos negócios realizados.

Ao serem avaliados o comportamento de exportação de Brasil e EUA, é possível identificar oscilações interessantes, principalmente entre as safras de 2008 e 2011, quando o segundo se classificava como o maior exportador. A partir de 2011 ambos os países mantiveram percentuais de exportações muito próximos, com alteração apenas a partir de 2016, quando houve crescimento das exportações brasileiras e queda das exportações norte-americanas.

Para avaliar de maneira mais específica a concentração de mercado, como descrito nos procedimentos metodológicos, foi realizada a análise em $\mathrm{CR}(\mathrm{k})$ de como esse mercado de exportação de soja concentra-se, conforme a Tabela 9.

Tabela 9 - Índices de concentração de mercado (em \%) CR(k) - CR(2); CR(4)

\begin{tabular}{|c|c|c|c|c|c|c|c|c|c|c|c|c|}
\hline & $\begin{array}{l}2008 \\
2009 \\
\text { CR(2) }\end{array}$ & $\begin{array}{l}2008 \\
2009 \\
\text { CR(4) }\end{array}$ & $\begin{array}{l}2009 \\
2010 \\
\text { CR(2) }\end{array}$ & $\begin{array}{l}2009 \\
2010 \\
\text { CR(4) }\end{array}$ & \begin{tabular}{|l}
2010 \\
2011 \\
CR(2)
\end{tabular} & $\begin{array}{l}2010 \\
2011 \\
\text { CR(4) }\end{array}$ & $\begin{array}{l}2011 \\
2012 \\
\text { CR(2) }\end{array}$ & $\begin{array}{l}2011 \\
2012 \\
\text { CR(4) }\end{array}$ & $\begin{array}{l}2012 \\
2013 \\
\text { CR(2) }\end{array}$ & $\begin{array}{l}2012 \\
2013 \\
\text { CR(4) }\end{array}$ & \begin{tabular}{|l|}
2013 \\
2014 \\
CR(2)
\end{tabular} & $\begin{array}{l}2013 \\
2014 \\
\text { CR(4) }\end{array}$ \\
\hline Brasil & 39,0 & 39,0 & 30,8 & 30,8 & 32,3 & 32,3 & 40,2 & 40,2 & 38,9 & 38,9 & 41,5 & 41,5 \\
\hline EUA & 45,3 & 45,3 & 43,9 & 43,9 & 44,1 & 44,1 & 40,9 & 40,9 & 35,8 & 35,8 & 39,6 & 39,6 \\
\hline Argentina & - & 7,3 & - & 14,1 & - & 9,9 & - & 8,4 & - & 12,5 & - & 7,0 \\
\hline Paraguai & - & 3,0 & - & 6,1 & - & 7,2 & - & 3,4 & - & 5,6 & - & 4,3 \\
\hline Canadá & - & - & - & - & - & - & - & - & - & - & - & - \\
\hline Outros & - & - & - & - & - & - & - & - & - & - & - & - \\
\hline Total & 84,3 & 94,5 & 74,7 & 94,9 & 76,4 & 93,6 & 81,1 & 92,9 & 74,7 & 92,7 & 81,1 & 92,4 \\
\hline & $\begin{array}{l}2014 \\
2015 \\
\text { CR(2) }\end{array}$ & $\begin{array}{l}2014 \\
2015 \\
\text { CR(4) }\end{array}$ & $\begin{array}{l}2015 \\
2016 \\
\text { CR(2) }\end{array}$ & $\begin{array}{l}2015 \\
2016 \\
\text { CR(4) }\end{array}$ & $\begin{array}{l}2016 \\
20 / 17 \\
\text { CR(2) }\end{array}$ & $\begin{array}{l}2016 \\
2017 \\
\text { CR(4) }\end{array}$ & $\begin{array}{l}2017 \\
2018 \\
\text { CR(2) }\end{array}$ & $\begin{array}{l}2017 \\
2018 \\
\text { CR(4) }\end{array}$ & $\begin{array}{l}2018 \\
2019 \\
\text { CR(2) }\end{array}$ & $\begin{array}{l}2018 \\
2019 \\
\text { CR(4) }\end{array}$ & $\begin{array}{l}2019 \\
2020 \\
\text { CR(2) }\end{array}$ & $\begin{array}{l}2019 \\
2020 \\
\text { CR(4) }\end{array}$ \\
\hline Brasil & 40,1 & 40,1 & 41,0 & 41,0 & 42,8 & 42,8 & 49,8 & 49,8 & 51,8 & 51,8 & 50,2 & 50,2 \\
\hline EUA & 39,7 & 39,7 & 39,9 & 39,9 & 40,0 & 40,0 & 37,9 & 37,9 & 31,2 & 31,2 & 33,7 & 33,7 \\
\hline Argentina & - & 8,4 & - & 7,5 & - & 4,8 & - & - & - & 5,2 & - & 5,3 \\
\hline Paraguai & - & 3,6 & - & 4,1 & - & 4,2 & - & 3,9 & - & 3,8 & - & 4,1 \\
\hline Canadá & - & - & - & - & - & - & - & 3,2 & - & - & - & - \\
\hline Outros & - & - & - & - & - & - & - & - & - & - & - & - \\
\hline Total & 79,8 & 91,8 & 80,9 & 92,5 & 82,8 & 91,7 & 87,7 & 93,0 & 83,0 & 92,0 & 84 & 93,4 \\
\hline
\end{tabular}

Fonte: Elaborada pelos autores.

Para cada ano foram realizadas análises sobre os dois principais agentes do mercado no que diz respeito à participação nas vendas totais e, posteriormente, à avaliação do $\mathrm{CR}(4)$, ou seja, análise dos quatro principais exportadores de soja com o objetivo de verificar o quanto do mercado total esse grupo restrito de vendedores controla. 
Com base nos cálculos realizados, pode-se observar que, desde 2008 até 2019, os dois maiores exportadores de soja controlaram entre $75 \%$ e $87 \%$ do mercado. Se essa análise for extrapolada para o grupo dos quatro maiores exportadores, esses valores chegam a $94,88 \%$ de toda a soja que é comercializada por exportação no mundo, indicando que o mercado desta commodity é altamente concentrado. Destaca-se que o Brasil se apresenta como principal agente de vendas durante boa parte do período analisado.

Para completar a análise foi utilizado outro índice de avaliação da concentração do mercado, chamado de Índice Hirschman-Herfindahl (IHH). Este á composto pela soma dos quadrados das concentrações de mercado identificadas $C R(k)$ e varia seu resultado entre os valores de zero e um. Assim, quanto mais próximo de 1 for o resultado, mais concentrado é o mercado, e quanto mais próximo de zero chegar o $\mathrm{IHH}$, menos concentrado será este. A Tabela 10 apresenta os valores quadrados da concentração de cada país analisado, bem como o valor final da soma dos mesmos.

Tabela 10 - Índice Hirschman-Herfindahl (IHH)

\begin{tabular}{|c|c|c|c|c|c|c|c|c|c|c|c|c|}
\hline & $\mathbf{2 0 0 8}$ & $\mathbf{2 0 0 9}$ & $\mathbf{2 0 1 0}$ & $\mathbf{2 0 1 1}$ & $\mathbf{2 0 1 2}$ & $\mathbf{2 0 1 3}$ & $\mathbf{2 0 1 4}$ & $\mathbf{2 0 1 5}$ & $\mathbf{2 0 1 6}$ & $\mathbf{2 0 1 7}$ & $\mathbf{2 0 1 8}$ & $\mathbf{2 0 1 9}$ \\
& $\mathbf{2 0 0 9}$ & $\mathbf{2 0 1 0}$ & $\mathbf{2 0 1 1}$ & $\mathbf{2 0 1 2}$ & $\mathbf{2 0 1 3}$ & $\mathbf{2 0 1 4}$ & $\mathbf{2 0 1 5}$ & $\mathbf{2 0 1 6}$ & $\mathbf{2 0 1 7}$ & $\mathbf{2 0 1 8}$ & $\mathbf{2 0 1 9}$ & $\mathbf{2 0 2 0}$ \\
\hline Brasil & 0,152 & 0,095 & 0,104 & 0,161 & 0,151 & 0,173 & 0,161 & 0,168 & 0,183 & 0,248 & 0,269 & 0,252 \\
\hline EUA & 0,205 & 0,193 & 0,194 & 0,167 & 0,128 & 0,157 & 0,158 & 0,159 & 0,160 & 0,144 & 0,097 & 0,114 \\
\hline Argentina & 0,005 & 0,020 & 0,010 & 0,007 & 0,016 & 0,005 & 0,007 & 0,006 & 0,002 & 0,000 & 0,003 & 0,003 \\
\hline Paraguai & 0,001 & 0,004 & 0,005 & 0,001 & 0,003 & 0,002 & 0,001 & 0,002 & 0,002 & 0,002 & 0,001 & 0,002 \\
\hline Canadá & 0,001 & 0,001 & 0,001 & 0,001 & 0,001 & 0,001 & 0,001 & 0,001 & 0,001 & 0,001 & 0,001 & 0,001 \\
\hline Outros & 0,001 & 0,001 & 0,001 & 0,001 & 0,002 & 0,002 & 0,003 & 0,002 & 0,003 & 0,001 & 0,002 & 0,001 \\
\hline Total & 0,365 & 0,313 & 0,316 & 0,339 & 0,301 & 0,339 & 0,331 & 0,337 & 0,351 & 0,396 & 0,373 & 0,373 \\
\hline
\end{tabular}

Fonte: Elaborada pelos autores.

Com base naquilo que foi apresentado por Schmidt e Lima (2002), a análise dos valores resultantes do IHH serve para identificar o nível de concentração do mercado. Quando estes são inferiores a 0,10 o mercado é desconcentrado, valores entre 0,10 e 0,18 indicam um aumento na concentração, já resultados acima de 0,18 apresentam-se para os casos em que já existe concentração do mercado avaliado.

Segundo os dados da Tabela 10, durante todo o período analisado, entre 2008 e 2019, o mercado de exportação de soja apresentou IHH acima de 0,30, reforçando o entendimento de que este se caracteriza como um mercado concentrado, com poucos agentes responsáveis pela maior parte do atendimento da demanda e do market share, contrapondo, desta forma, o que foi apresentado por Zemolin (2013), de que o mercado de commodities aproxima-se de um mercado perfeitamente competitivo em razão da grande quantidade de agentes participantes da oferta e demanda, pois observam-se indicativos de concentração, uma vez que o mercado em análise apresentou IHH acima de 0,30 .

O Gráfico 2 apresenta a variação dos valores resultantes do cálculo do Índice Hirschman-Herfindahl (IHH) durante os anos, para um melhor entendimento sobre as alterações sofridas na concentração do mercado durante o período de análise. 


\section{Gráfico 2 - Variação Índice Hirschman-Herfindahl (IHH)}

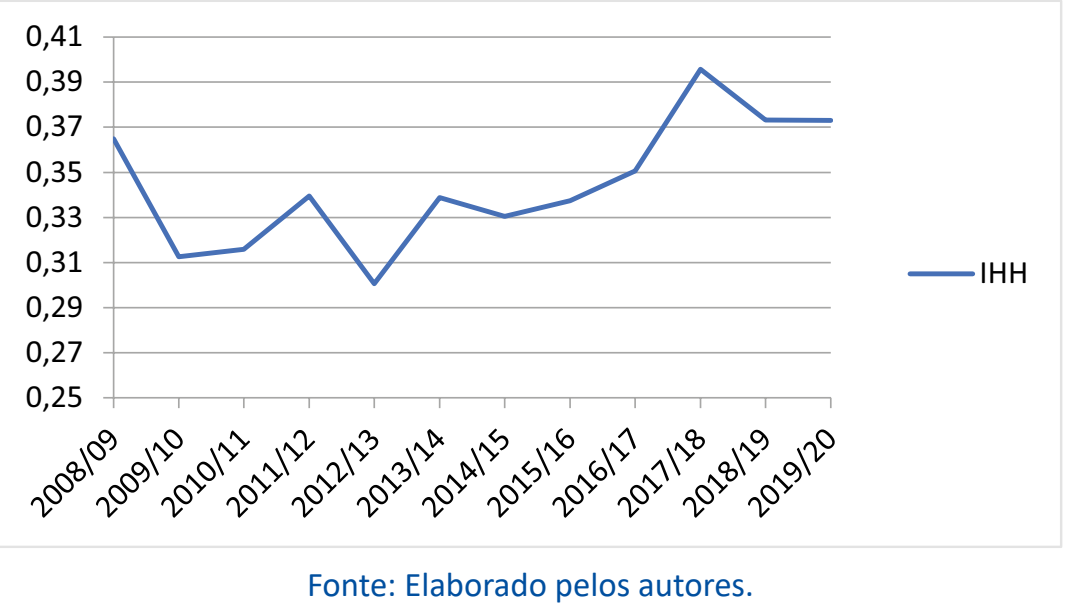

Nota-se que entre os anos de 2008 e 2012, embora algumas alterações tenham se apresentado, tanto quanto o aumento quanto à diminuição de concentração houve uma queda no $\mathrm{IHH}$, representando que as exportações de soja estavam tendendo a uma situação de maior concorrência e participação mais significativa de outros países no mercado mundial, além de Brasil e EUA. A partir de 2013, contudo, a concentração deste mercado passou a se solidificar, atingindo valores do índice próximos a 0,40 , mas se estabilizando próximo a 0,37 nos últimos anos, de modo que a classificação de tal mercado se mantém como algo fortemente concentrado e limitado a um grupo restrito de agentes.

\section{CONCLUSÕES}

O presente estudo teve como objetivo analisar a participação do Brasil nas exportações mundiais de soja por meio do uso de índices e ferramentas de mensuração de concentração de mercado, como o $\mathrm{CR}(\mathrm{k})$ e o Índice Hirschman-Herfindahl (IHH), auxiliando no entendimento da caracterização do mercado mundial desse grão.

Inicialmente foram avaliados dados sobre a produção da soja no mundo e em partes específicas, como na América do Sul, Brasil, Estados Unidos e dois Estados do território nacional. Essas informações já permitiram, a princípio, identificar como a concentração das exportações de soja se apresenta, uma vez que apenas dois países somaram a maior parte da produção deste grão no ano de 2019. No que concerne ao território nacional, dois Estados se destacaram - Mato Grosso e Rio Grande do Sul - com altos valores de produção em comparação com o total gerado pelo Brasil. Sozinho, o Estado do MT produz mais de um terço de toda a soja nacional, distanciando-se, consideravelmente, do segundo colocado (Rio Grande do Sul), que produz $40 \%$ menos do que este.

Em seguida realizou-se análise sobre a evolução das exportações brasileiras do produto, sendo apresentado crescimento significativo nestas, somando $371 \%$ de aumento entre os anos de 2005 e 2018, além de maiores ganhos monetários em razão de tal crescimento.

Posteriormente, a análise inicial de concentração listou alguns dos principais produtores e exportadores de soja no mundo, incluindo Brasil, Estados Unidos, China, Índia, Argentina e Paraguai. Avaliando a participação de mercado de cada um, concluiu- 
-se que, apesar de representarem uma parcela importante de negócios em suas regiões, o mercado se concentra, fortemente, em apenas dois agentes - Brasil e EUA -, de modo que, juntos, são responsáveis por mais de $80 \%$ de tudo o que é produzido e vendido desta commodity no mundo. No que diz respeito ao cenário mundial dos principais produtores da soja, destaca-se a questão da Argentina, vizinha do Brasil, que vem sofrendo com reduções em sua produção, principalmente em razão de questões climáticas.

Especificamente no que se refere às exportações, no início do período analisado os norte-americanos classificavam-se como os principais exportadores mundiais, com representatividade de mais de $40 \%$ do mercado global, sendo o Brasil posicionado em segundo com participação média de $32 \%$ do total. A partir do ano de 2012, contudo, houve queda na participação dos EUA nas exportações mundiais, associado ao crescimento do volume de negócios brasileiros, fazendo com que o Brasil passasse a se classificar como o mais importante comerciante mundial de soja, chegando a representar, sozinho, mais de $50 \%$ das exportações totais entre 2018 e 2019. Ainda quanto a essa classificação, nota-se importante a China como um dos principais compradores de soja do Brasil, intensificando as vendas e se mostrando como um país de grande potencial para a ampliação da produção, em razão da crescente demanda apresentada na região.

Por último foi utilizado o Índice Hirschman-Herfindahl (IHH) para avaliar a concentração de mercado, de modo a gerar valores entre zero e um para a identificação de mercados concentrados ou não. Após a realização dos cálculos, observou-se que, segundo os resultados apresentados, o mercado mundial de soja classifica-se como concentrado (IHH médio de 0,30), apontando para o fato de que poucos países representam parte significativa das vendas mundiais, sendo identificada, principalmente, uma forte concentração do mercado mundial de soja, quando poucos países representam parte significativa das vendas mundiais, notadamente EUA e Brasil.

O Brasil apresenta um desempenho bastante positivo e estável na sua condição de produtor e exportador do produto soja, juntamente com os EUA. Juntos, esses dois países apresentam-se como os principais players nesse mercado. Em particular, a competitividade do Brasil deve-se, em grande parte, às suas vantagens comparativas relacionadas às suas condições naturais, bem melhores que as dos outros países produtores de soja. Políticas públicas também têm contribuído para isso, como é o caso da Lei Kandir.

Diante da confortável posição do Brasil nesse mercado, cabe refletir quais elementos atuais e futuros podem vir a influenciar, positiva ou negativamente, essa posição. Assim, algumas questões foram pontuadas ao longo dos resultados. A competitividade do Brasil em relação aos outros países que também participam mais ativamente desse mercado e que poderiam, de alguma forma, ameaçar sua posição privilegiada, é ainda bastante proeminente e sustentável. No caso da Argentina, suas condições naturais e regulatórias dificilmente permitirão um crescimento expressivo no mercado da soja. Assim como a China, que, mesmo com investimentos significativos na soja, voltados para a produção interna ou externa como no Brasil, também dificilmente alcançará os níveis de produção brasileiros.

De fato, o Brasil continuará tendo os EUA como principal concorrente no mercado da soja. Desta forma, cabe ao país continuar investindo no setor por meio de desenvolvimento tecnológico, assim como do aumento de áreas de plantio, sempre em equilí- 
brio com as questões ambientais e sociais, as quais têm sido amplamente consideradas como fatores importantes para a competitividade mundial dos países e para garantir um bom desempenho com base não só em vantagens comparativas, baseadas em condições naturais, mas também em fatores como qualidade, infraestrutura logística, restrições tributárias e financeiras, assim como em aspectos de coordenação desse SAG, de modo que os agentes possam construir de forma conjunta soluções para o fortalecimento e o desenvolvimento sustentável do setor no mercado mundial.

\section{REFERÊNCIAS}

AMARAL, D. F. Desmistificando o Programa Nacional de Produção e Uso de Biodiesel: a visão da indústria brasileira de óleos vegetais. 2009. Disponível em: http://www.abiove.com.br/palestras/abiove_relatorio_ biodiesel_ago09_br.pdf. Acesso em: 2 jul. 2013.

AZEVEDO, F. Análise da competitividade brasileira na exportação de soja. 2018. Trabalho de Conclusão de Curso - Universidade Pitágoras Unopar, ljuí, RS, 2018.

BATISTA FILHO, E. L. Aspecto da expansão da soja e geração de emprego rural no extremo oeste do Paraná - 1970/1990. 1994. Dissertação (Mestrado em Economia) - Universidade Federal da Paraíba, João Pessoa, 1994.

CONAB. Companhia Nacional de Abastecimento. Boletim das Safras de Grãos. Disponível em: https:// www.conab.gov.br/info-agro/safras/graos/boletim-da-safra-de-graos?start=10. Acesso em: 5 set. 2019.

CORONEL, D. A. Fontes de crescimento e orientação regional das exportações brasileiras do complexo soja. 2008. Dissertação (Mestrado) - Universidade Federal do Rio Grande do Sul, Porto Alegre, 2008.

CORONEL, D. A.; MACHADO, J. A. D.; CARVALHO, F. M. A. Análise da competitividade das exportações do complexo soja brasileiro de 1995 a 2006: uma abordagem de market-share. Revista de Economia Contemporânea, Rio de Janeiro, v. 13, n. 12, p. 281-307, 2009.

COSTA, N. L. et al. Desenvolvimento tecnológico, produtividade do trabalho e expansão da cadeia produtiva da soja na Amazônia Legal. In: SANTANA, A. C. (org.). Mercado, cadeias produtivas e desenvolvimento rural na Amazônia. 1. ed. Belém, PA: Ufra, 2014. p. 81-112. V. 1.

EMBRAPA. Empresa Brasileira de Pesquisa Agropecuária. Dados econômicos - Portal Embrapa. Soja em números (safra 2018/19). 2019. Disponível em: https://www.embrapa.br/soja/cultivos/soja1/dados-economicos. Acesso em: 22 ago. 2019.

FEDERIZZI, L. C. A soja como fator de competitividade no Mercosul: histórico, produção e perspectivas futuras. 2005. Disponível em: http://www.fee.tche.br/sitefee/download/jornadas/2/e13-10.pdf. Acesso em: 2 jul. 2013.

FIESP. Federação das Indústrias do Estado de São Paulo. Safra mundial de soja. 2019. Disponível em: https://www.fiesp.com.br/indices-pesquisas-e-publicacoes/safra-mundial-de-soja/. Acesso em: 10 ago. 2019.

FERRAZ, J. C.; KUPFER, D.; HAGUENAUER, L. Made in Brazil: desafios competitivos para a indústria. Rio de Janeiro: Campus, 1995.

GASQUES, J. G. et al. Competitividade de grãos e de cadeias selecionadas do agrobusiness. Brasília: Ipea, 1998. Disponível em: http://www.ipea.gov.br/portal/index.php?option=com_content\&view=article\&id=3802. Acesso em: 2 jul. 2013.

GU, H.; PATTON, D. China prevê maior safra de soja em 14 anos no ciclo 2019/20. Reuters, Pequim, 10 maio 2019. Disponível em: https://economia.uol.com.br/noticias/reuters/2019/05/10/china-preve-maior-safra-de-soja-em-14-anos-no-ciclo-201920.htm?cmpid=copiaecola. Acesso em: 24 set. 2019.

GUJARATI, D. N. Econometria básica. 3. ed. São Paulo: Makron Books do Brasil, 2000.

ICONE. Instituto de Estudo do Comércio e Negociações Internacionais. Análise estratégica para a produção de soja responsável no Brasil e Argentina. Disponível em: http://www.ifc.org/wps/wcm/connect/ cd60bf004a96003aad4aedeec99f439e/Soja+Gap+Analysis. portugues.pdf?MOD=AJPERES. Acesso em: 30 out. 2013.

LAZZARINI, S. G.; NUNES, R. Competitividade do sistema agroindustrial da soja. São Paulo: Pensa; USP, 2000.

LOVATELLI, C. O caso de sucesso do agronegócio de soja no Brasil. In: PALESTRA DO FARMERS CLUB - Reino Unido, São Paulo, 2009. Disponível em: http://www.abiove.com.br/palestras/abiove_palestra_ukfarmers_mar09_br.pdf. Acesso em: 2 jul. 2013. 
MACEDO, I. C.; NOGUEIRA L. A. H. Avaliação do biodiesel no Brasil. Brasília: Núcleo de Assuntos Estratégicos da Presidência da República, 2005. 233p.

MALHOTRA, N. K. Pesquisa de marketing: uma orientação aplicada. Tradução Nivaldo Montigelli e Alfredo Alves. 3. ed. Porto Alegre: Bookman, 2001.

MARCONI, M. A.; LAKATOS, Eva Maria. Técnicas de pesquisa. 5. ed. São Paulo: Atlas, 2002.

MARTIN, S. Industrial economics: economic analysis and public policy. 2. ed. New Jersey: Prentice Hall, 1993.

MDIC. Ministério da Economia, Indústria, Comércio Exterior e Serviços. Estatísticas de Comércio Exterior. 2019. Disponível em: http://www.mdic.gov.br/index.php/comercio-exterior/estatisticas-de-comercio-exterior. Acesso em: 11 ago. 2019.

NASSAR, A.; ANTONIAZZI, L. B. Análise estratégica para produção de soja responsável no Brasil e na Argentina. São Paulo: Instituto Icone, 2011. Disponível em: http://www.ifc.org/wps/wcm/connect/cd60bf004a96003aad4aedeec99f439e/Soja+Gap+Analysis.portugues.pdf?MOD=AJPERES. Acesso em: 2 jul. 2013.

NEGRI, F. D. Padrões tecnológicos e de comércio exterior das firmas brasileiras. In: NEGRI, J. A. D; SALERNO, M. S. (org). Inovações, padrões tecnológicos e desempenho das firmas industriais brasileiras. Brasília: Ipea, 2005. p. 75-118.

PIMENTA, I. Brasil x Argentina da soja: a diferença na evolução do cultivo nas últimas cinco safras. Notícias Agrícolas, São Paulo, 9 ago. 2017. Disponível em: https://www.noticiasagricolas.com.br/noticias/soja/196767-brasil-x-argentina-da-soja-a-diferenca-na-evolucao-do-cultivo-nas-ultimas-cinco-safras.html\#. XZOZJOZKjIW. Acesso em: 24 set. 2019.

RESENDE, M. Medidas de concentração industrial: uma resenha. Análise Econômica, v. 12, p. 24-33, 1994. RESENDE, M.; BOFF, H. Concentração industrial. In: KUPFER, D.; HASENCLEVER, L. (org.). Economia industrial: fundamentos teóricos e práticos no Brasil. Rio de Janeiro: Campus, 2002. p. 73-90.

ROCHA, L. E. V.; MENDONÇA, T. G. Desempenho das exportações de soja em grão: uma análise de constant-market-share. In: Congresso da Sociedade Brasileira de Economia e Sociologia Rural, 42., 2004, Mato Grosso. Anais... Mato Grosso: Sober, 2004.

SAMPAIO, L. M. B.; SAMPAIO, T.; BERTRAND, J. P. Fatores determinantes da competitividade dos principais países exportadores do complexo soja no mercado internacional. Organizações Rurais \& Agroindustriais, Lavras, v. 14, n. 2, p. 227-242, 2012.

SCHMIDT, C. A. J.; LIMA, M. A. de. Índices de concentração. 2002. Disponível em: www.seae.fazenda.gov. br/central_documentos/.../2002.../doctrab13.pdff. Acesso em: 22 ago. 2017.

UNDATA. Statistcs. Disponível em: http://data.un.org/Data.aspx?d=ComTrade\&f=_I1Code\%3a13. Acesso em: 18 jun. 2013.

USDA. United States Department of Agriculture. Oilseeds: World Markets and Trade. Disponível em: https://usda.library.cornell.edu/concern/publications/tx31qh68h?locale=en. Acesso em: 10 ago. 2019.

ZEMOLIN, E. M. Análise da evolução da competitividade e da inserção externa do complexo soja brasileiro. 2013. Dissertação (Mestrado) - Universidade Federal do Rio Grande do Sul, Porto Alegre, 2013.

ZIKMUND, W. G. Princípios da pesquisa de marketing. 2. ed. São Paulo: Thomson, 2006. 